Valerie Forrestal

S.C. Williams Library

Stevens Institute of Technology

Castle Point on Hudson

Hoboken, NJ 07030

valerie.forrestal@stevens.edu

Keywords: emerging technologies, library 2.0, marketing, microblogging, outreach, social media, Twitter, web 2.0, web services

Abstract: This article highlights the advantages of librarians and libraries establishing a professional or institutional presence on Twitter. This basic introduction to the web service also discusses innovative ways to shape your Twitter account into a successful professional development, reference, and outreach resource.

\title{
Making Twitter Work: a Guide for the Uninitiated, the Skeptical, and the Pragmatic
}

\section{VALERIE FORRESTAL}

Communications and New Media Strategies Librarian, Stevens Institute of Technology, Hoboken, NJ

Regardless of what enthusiasts and detractors touting Twitter's boom or doom may say, the service continues to grow at a steady pace (Weil 2010). According to a recent Pew Internet study, one in five internet users is now using online status updating services, such as Twitter (Fox et al. 2009). However, despite its popularity, many continue to poke fun the rampant “navel-gazing” and banal status updates, such as the oft-cited "what I had for breakfast” posts (Johnson 2009).

How have so many in the library community found value in such a mundane application? The answer may lie in sheer numbers. As of summer 2010, the Twitter directories WeFollow and Twellow list 996 and 7,977 librarians using Twitter, respectively (http://wefollow.com/twitter/librarian \& http://www.twellow.com/category_users/cat_id/1059), and one estimate places the number of library Twitter accounts at approximately 830 (Brown 
2010). These numbers are rough at best, but even conservative estimates of the activity of librarians and libraries on Twitter make the time investment worthwhile. In fact, the author of a recent study on measuring influence on Twitter cited an unnamed librarian as being one of the most influential non-celebrity users on the service (Young 2010).

So, what is Twitter and how does it work? In brief terms, Twitter allows you to post short status updates (up to 140 characters each post, including spaces) online. People will follow, or subscribe to, your content to see your posts, called "tweets." Likewise, you can follow other people's accounts to see their updates. Your account can be public (viewable to anyone on the internet) or private (users must request your permission to view your updates).

To talk to, mention, or reference a specific user, you would use the “@” symbol followed by the desired username (e.g., @val_forrestal) within the tweet. If you tweet something that another user finds interesting or useful, he or she can retweet it by placing an "RT" along with a reference to the original poster in front of the original tweet.

Finally, you can use a hashtag, or the “\#” symbol, to tag a post with specific keywords. Often events will have a preordained hashtag so that users attending the event can find each other's tweets and those not attending can follow along from another location.

There are plenty of ways to access Twitter: through the Twitter.com web site or using desktop applications, such as TweetDeck or Seesmic. Twitter also has a mobile application (which also works on the iPad) that allows you to sign into several accounts at once, making it easy to switch between personal and institutional accounts. The mobile client also makes attaching pictures and video to your tweets simple and allows for quick URL shortening for long Internet addresses, which can quickly consume your 140 character limit. 
If you do not have a smartphone, you can use short message service (SMS; or text messaging) to send and receive messages. You can consult Twitter's Help Center for more information on setting up your phone to use the service, either through their mobile web site, app, or SMS/text messaging (http://www.support.twitter.com/articles/14014-twitter-phone-faqs).

Whether tweeting from your personal account or your library's, the most important factor in creating a meaningful and useful experience is to realize that the service provides the means for conversation not just broadcasting. Even your most ordinary tweets can connect you with others within your community if a conversation builds around them. In this spirit, get comfortable with just jumping right in. Talk to people you do not know; respond to their updates if they interest you; or retweet posts that you think will be useful or interesting to your followers. The worst that can happen is that you will be ignored, but in general people use Twitter for the interaction and they enjoy it.

Another tip for creating engagement within Twitter, especially for library or institutional accounts, is to create RSS feeds for certain searches. Even if you don't know what an RSS feed is, this is quite easy to do. Just go to Twitter's search interface (http://search.twitter.com) and do a search for the name of your library, then click the "feed for this query" link. You can also search for a keyword mentioned within a vicinity of your location. (Use the advanced search for these more complex queries.) If you do not want to use an RSS feed reader (such as Google Reader) to view your search results, there are many services that will send you an e-mail update to alert you when your keywords are mentioned (TweetAlarm, Twilert, and tweetbeep are just a few). 
Twitter search alerts essentially allow you to use Twitter as a "proactive” reference tool. For example, you can be notified if someone uses the terms "research," "paper," or "writing” on Twitter within a mile of your location, giving you an opportunity to respond to the poster with research options at your library even if the user does not mention the word "library." With that information, you can reach out to potential library users, who many not even know where to look for assistance, and establish a connection that will bring them in your door (or to your resources).

You can also use search alerts as a "virtual comment box" by giving you a way to actively monitor what people are saying about your library and address their concerns personally. In this capacity, Twitter can be tapped for user feedback and can lead to "thinking-out-of-thebox” ideas for new services or resources.

Speaking of RSS feeds, although Twitter use is increasing, there are many people who do not use the service. You can still reach these people by creating an RSS feed of your updates and publishing it on your web site, your blog, or even your online or e-mail newsletter. There are also services (such as Yakket and Ping) that allow you to automatically send your Twitter updates to your library's Facebook page. These tools allow you to use Twitter to get updates out to your community quickly and easily without the necessity of creating a longer blog post about them.

Twitter's mobile app and SMS service also mean that it is much easier to send out updates from anywhere at any time, so you can pass along pertinent information as it comes along, not just during business hours.

Overall, Twitter is a great way to remind people about events and services, pass along important announcements, as well as to share information that might be only tangentially related to you or your library (such as information from a publisher or a group within your community). 
In fact, using Twitter to reiterate or amplify the voices in your greater community (by retweeting them or just helping promote their events or concerns through your Twitter account) breeds goodwill toward you and your library.

One particularly innovative use of Twitter by a library is Harvard Library Innovation Laboratory’s project, “Library Hose,” which generates a tweet every time someone checks out a book from any of their branch libraries and aggregates them to a webpage (http:/librarylab.law.harvard.edu/twitter/). Although just an experimental project (which was temporarily suspended as of September 15, 2010), it served as an interesting way to show just how popular and vital Harvard University's libraries are.

Another tip for making the best use of your Twitter presence, especially if it is an institutional one, is to have a strategy in place before diving in (Grabowska 2010):

- Think about the purpose of your account and what you would like to focus on.

- Make sure to have a picture, a bio, and a link to your web site, if available, for credibility (that goes for both personal and library accounts).

- Make sure the appearance of your page matches with your overall branding scheme by using your logo and official colors.

For official accounts, you should also have a best practices guide which outlines your purposes and goals, and general rules for behavior and interaction. A great starting point is Brian Solis' (2010) recent post on the social media blog, Mashable, which sets out 21 "rules of engagement” for any social media campaign or presence. One of his notable points recommends moving beyond marketing into becoming a real participant in your online community. It is extremely important to foster conversation and interaction and to listen and react to your users' 
concerns and needs. Doing so not only breeds trust, but also inspires advocacy on your part, something of which today’s libraries are in dire need.

There are also several good library-specific social media best practices and policy guides that you can use as a starting point for your institution. Posted recently on the blogs, Tame the Web and Librarians Matter, they recommend being honest, professional, conversational, helpful, and respectful (Greenhill and Fay 2010). They also warn that, although you should aim to be as transparent and open as possible, you should be careful not to divulge confidential information (Stephens 2010). Probably the most important rule with any institutional social media account is to check it regularly, especially if you are using it in a reference capacity. Users will quickly grow frustrated with an organization that ignores their questions and concerns, even if they suspect you are not intentionally doing so. Libraries implementing these types of services should have a point person who is held responsible for regularly checking and updating the accounts, even if several people have access to them (Murphy 2010).

Finally, a story: when I first started my library’s Twitter account, I took a lot of flak about it. Some people at my institution felt that I was wasting work time on a purely recreational and narcissistic medium. Then, one day a Twitter search that I had set up as an RSS feed alerted me that someone had mentioned my place of work in a tweet. A graduating student complained that his school e-mail account, which kept him informed on news and events relating to the school, was being disconnected. I responded to this student on Twitter, sending him a list of the school's Twitter accounts and Facebook pages. The student was pleased and wrote a blog post about this experience. I then took the time to comment on his post, thanking him for writing about us. 
This story taught me a few lessons about Twitter's potential value in my community. One is that students are more likely to donate and be active alumni if they have methods of easily maintaining a tie to the school. Another is that Twitter can act as a starting point for greater conversation. If it sparks an interaction, you should be willing to take that interaction to other places the user may be. If you direct them to a Facebook page or blog, continue the conversation there. If they are more comfortable moving the conversation to e-mail or the phone, be accommodating.

Twitter is invaluable for creating a network of colleagues who connect me not only to other people of relevance to me, but also to relevant information, events, breaking news, and professional development resources. This network is almost always responsive and available to bounce ideas off of, get the word out, and even answer reference questions. They allow me vicariously to attend conferences and workshops that I cannot attend in person and expose me to sources and viewpoints that I would not have encountered on my own. This community of active professionals, and the ongoing conversations that surround them, brings vitality to the profession that can only serve to keep the field relevant and vibrant, acting as a catalyst to advance libraries into the future.

\section{REFERENCES}

Brown, Lindy. 2010. “Libraries on Twitter (Updated List).” Circulation, September 19. Accessed September 21, 2010. http://lindybrown.com/blog/2009/01/libraries-on-twitter-updated-list/.

Fox, Susannah, Kathryn Zickuhr, and Aaron Smith. 2009. “Twitter and Status Updating, Fall 2009.” Pew Internet \& American Life Project, October 21. Accessed June 1, 2010. http://www.pewinternet.org/Reports/2009/17-Twitterand-Status-Updating-Fall2009.aspx?r=1. 
Grabowska, Kasia. 2010. “Social Media Best Practices for Libraries: A TTW Guest Post.” Tame The Web, March 18. Accessed September 16, 2010.

http://tametheweb.com/2010/03/18/social-media-best-practices-for-libraries/.

Greenhill, Kathryn, and Jean Hing Fay. 2010. “A Social Media Policy for a One Branch Public Library.” Librarians Matter, September 10. Accessed September 16, 2010.

http://librariansmatter.com/blog/2010/09/10/a-social-media-policyfor-a-one-branch-publiclibrary/.

Johnson, Steven. 2009. “How Twitter Will Change the Way We Live.” Time, June 5. Accessed June 1, 2010. http://www.time.com/time/business/article/0,8599,1902604,00.html.

Murphy, Joe. 2010. “Management Models and Considerations for Virtual Reference.” Science \& Technology Libraries 29: 176. doi:10.1080/01942620802205579.

Solis, Brian. 2010. “21 Rules for Social Media Engagement.” Mashable, The Social Media Guide, May 18. Accessed June 1, 2010. http://mashable.com/2010/05/18/rules-social-mediaengagment/.

Stephens, Michael. 2010. “Anytown Public Library’s Social Media Policy.” Tame The Web, June 10. Accessed September 16, 2010.http://tametheweb.com/2010/06/10/anytown-publiclibrarys-social-media-policy/.

Weil, Kevin. 2010. “Measuring Tweets.” Twitter Blog, February 22. Accessed June 1, 2010. http://blog.twitter.com/2010/02/measuring-tweets.html.

Young, Jeff. 2010. “Researchers Find 'Million-Follower Fallacy' in Twitter.” The Chronicle of Higher Education. Wired Campus, May 25. Accessed June 1, 2010. http://chronicle.com/blogPost/Researchers-Find/24290/. 